\title{
Experiencing nature with sight impairment: seeking freedom from ableism
}

\author{
Author: Sarah L Bell*
}

*Corresponding Author: European Centre for Environment and Human Health, University of Exeter Medical School, Knowledge Spa, Treliske, Truro, Cornwall, TR1 3HD, UK. Email: Sarah.Bell@exeter.ac.uk

\begin{abstract}
The idea of nature as freedom has long captured the human imagination, particularly since the Romantic era when notions of escapism were underpinned by the idealisation and externalisation of nature. The drive for freedom persists in the findings of much contemporary research examining the contribution of nature to human health and wellbeing. Yet, this work tells us little about how cultural narratives of freedom play out in the lives of people living with impairment and disability, or the constraining ableist assumptions that often underpin popular discourses of nature. This paper aims to address this, drawing on the findings of an in-depth qualitative study exploring how 31 people with varying forms and severities of sight impairment, living in rural and urban areas of England, describe their experiences with(in) diverse types of nature through the life course. Moving beyond the 'wilderness ideal' and sensationalised 'supercrip' stories that reproduce ableist ideas of bodies without limitation, this paper foregrounds the richly textured ways in which participants experienced feelings of freedom with nonhuman nature. These freedoms are characterised as social, mobile and exploratory. In doing so, it seeks to make room for a range of nature experiences, folding social justice into the growing momentum to connect people with nature in the name of health and wellbeing.
\end{abstract}


Keywords: sight impairment, disability, ableism, nature, freedom, social justice.

\section{Highlights:}

- Explores the relevance of cultural narratives of 'nature as freedom' amongst people living with sight impairment.

- Foregrounds the ableist assumptions underpinning current ideas of independent nature access.

- Characterises three forms of freedom: social, mobile and exploratory.

- Calls for an emancipatory body politics that recognises all bodies as equal and interdependent. 


\section{Introduction}

The idea of nature as freedom has long captured the human imagination (Macnaghten and Urry, 1998), particularly since the Romantic era when notions of escapism were underpinned by the idealisation and externalisation of nature (Stenning and Gifford, 2013). Such notions were characterised by a desire to escape the 'sensual constraints' of the city (Edensor, 2000), 'stepping out' of the 'human' world in search of the 'Picturesque' or the 'Sublime' (Smith, 2013). The idealisation of freedom in nature persists in much research examining the contribution of nature to human health and wellbeing (Conradson, 2005; Smaldone et al., 2005; Özgüner and Kendle, 2006). Indeed, the sensation of 'being away' is deemed central to experiences of 'attention restoration'; a widely (often uncritically) adopted theory in environmental psychology which suggests that so-called 'natural' environments - be they, parks, gardens, woodlands, coastlines etc. - capture our attention with little or no cognitive effort, allowing recovery and restoration from cognitive fatigue or stress (Hartig et al., 2014; Ohly et al., 2016).

Much of this work tends to focus on 'able bodied' encounters with nature (Burns et al., 2009; 2013; Morris et al., 2011; Horton, 2017), telling us little about how cultural narratives of freedom play out in the lives of people living with impairment, or the constraining ableist assumptions that often underpin popular discourses of nature and the most 'authentic' ways to experience it (Ray and Sibara, 2017). This paper aims to address this knowledge gap, responding to recent calls to 'look to disabled bodies and minds as a resource in thinking about our future natures differently' (Kafer, 2017: 204). To do so, it draws on the findings of an in-depth qualitative study exploring opportunities to promote 
more inclusive, multisensory nature experiences amongst people living with varying forms and severities of sight impairment in the UK.

\section{Locating 'nature' experiences within the social-relational model of disability}

Western society has long been fascinated by the aesthetic qualities of so-called 'natural' environments, from notions of freedom within 'untouched wilderness' to the reification of beauty, the picturesque and the sublime (Macnaghten and Urry 1998; Paterson, 2014). Much of this work, particularly within the wilderness movement, is underpinned by a 'hidden attachment' to 'the abled, hyperfit body', inadvertently leading to the 'physical exclusion of disabled people from the secluded landscapes of national parks' (Alaimo, 2017: ix). The limited experiences of people with impairment within this literature tend to oscillate between those conveyed as sub-human to those celebrated as super-human (Bolt 2014: 72). Sensationalised 'supercrip' stories, for example of impaired heroes scaling mountains, 'glorify individual willpower' (Ray, 2017:39) in the 'twinned conquest' (Kafer, 2017: 221) of simultaneously overcoming bodily impairment and the mountain, posing individual hard work rather than 'broad-based disability access as the key to success' (Clare, 2017a: 9). Such stories capture the headlines because 'disabled bodies are understood as incapable of physically demanding activities' (Ray, 2017: 40). At the same time, the nature settings that are routinely 'created' and managed with impairment in mind are often limited to short wheelchair accessible trails that circle a national park visitor centre, or a small sensory garden tucked into the corner of an otherwise expansive area of parkland or woodland. Although such efforts cater to the immediate senses of sight, sound and touch, they often fail to accommodate the kinaesthetic sense; the desire to move and explore the same 
diversity of habitats as everyone else (Bell, In Press). These responses to impairment largely reinforce the biomedical model of disability, a model that locates the condition of being disabled within the body. This model tends to equate disability with inability (Ray, 2017), seeking 'solutions' in the form of biomedical cures designed to eliminate embodied 'abnormalities' (Johnson, 2017). Such approaches perpetuate disability stereotypes that 'lodge' in the body (Clare, 2015), devaluing present day body-selves in favour of future projections. In doing so, they fail to recognise that people with impairment have lives to live now, lives 'that will be made better by material and attitudinal access' (Clare, 2017a: 86), whilst also ignoring the priorities of those who embrace 'impairment as part of human diversity and difference' (Beauchamp-Pryor, 2011: 7).

With this in mind, disability scholars have advocated a shift towards a socialrelational model of disability that acknowledges the physical discomfort experienced with impairment (Thomas, 2007) but locates 'the problems of injustice not in individual bodyminds but in the world' (Clare, 2017a: 13). Such a shift recognises the disabling influence of systems of oppression that unnecessarily limit how our environments are designed and managed, and the social structures and norms that 'privilege a particular sense of the human body that is constrictive, not expansive' (Johnson, 2017: 81). The social-relational model of disability encourages moves to counter interlocking systems of oppression, including but not limited to those characterised by 'ableism'; a form of discrimination enacted against people with impairment by 'promoting normalcy carried out through structural barriers, personal actions and theories' (Nocella, 2017: 149). Ableism affects what people feel they can be alongside what they can do (Reeve, 2002). In this way, people with impairment often face both physical barriers to participation (Kitchin, 1998) and social barriers, in the form of 
disabling discourses and stereotypical socio-cultural attitudes concerning people's embodied vulnerabilities and capabilities (Butler and Bowlby, 1997; Pow, 2000; Reeve, 2002).

It has been suggested that the social model of disability falters in nonhuman nature, that it cannot 'adequately address' the barriers, irregularities and challenges presented by natural environments, such as rocks, cliffs, steep mountains or sandy beaches (Shakespeare, 2014). Yet, as argued by Kafer (2017: 201), natural environments are also 'built' to varying degrees; be it physically/materially in terms of their management and design, or socially in our collective imagination regarding what nature is, who it is for and what kinds of experiences engender the most 'authentic' understandings of nature. These collective judgements often 'ignore the complicated histories of who is granted permission to enter nature, where nature is said to reside, how one must move in order to get there, and how one will interact with nature once one arrives in it' (Kafer, 2017: 207). Indeed, Tregaskis (2004) highlights how ableist discourses of vulnerability, risk and impairment have resulted in the labelling and exclusion of disabled bodies from many nature settings, equating 'abnormality' with 'deviance and danger' (Worth, 2013). Persistent preoccupations with risk management amongst outdoor service providers, and the desire to contain or control socalled 'risky' or 'deviant' bodies within controllable spatial boundaries, continue to undermine people's freedom to 'be' with nature in their own way and on their own terms (Burns et al., 2013).

Counter-movements have arisen to resist these misperceptions and stereotypes and reaffirm diverse embodiments as equally capable and competent. As noted by Saerberg (2010: 369) in relation to the 'blind style' of perception, there are other normalcies of space beyond culturally dominant constructions; 'not a single sense is missing when one sense is 
'missing'. It's just that the whole is composed of a different mixture of the senses'. Studies exploring diverse nonhuman nature embodiments convey such resistance. For example, participants in Macpherson's (2009a) study of visually impaired walkers in the Lake and Peak Districts illustrate the highly intricate bodily knowledge and multisensory competences that are developed by walkers in order to attune to, negotiate, embody and move through the often challenging terrains of these UK national parks. As one sight impaired walker commented:

'Partially sighted people have the capacity to walk, they develop skills, foot skills, for example... So often you have a better body awareness in space... your legs and feet are more sensitive to what is down underneath your feet and you read what is underground with your foot. So, showing sighted people that even though you don't see, you can do... But it's also about showing partially sighted people that they can do it. Because people lose their vision and they think they can't do it any more - they have the same stereotypes as any sighted person, so they turn it against themselves'.

In this extract, the walker emphasises the importance of challenging these stereotypes, both to confront societal prejudice but also to prevent the internalisation of such perceptions amongst people trying to adapt to sight loss; those caught between present and past embodiments of the world (Macpherson, 2009b).

Dominant stereotypes and ableist narratives tend to overlook the richly textured ways in which people may experience nature (Kafer, 2017); not to master it or to overcome 
impairment, but rather to ground oneself in the world, to know and feel part of nature, 'recognising common structures of bone, flesh, oxygen and air' (Kafer, 2017: 229). Moving beyond pervasive ableist rhetoric 'makes room for a range of experiences of human and nonhuman nature' (Kafer, 2017: 226), encouraging a commitment not just to biodiversity in nature but also to cultural and embodied diversity (Clare, 2017b). This paper foregrounds such experiences, highlighting the importance of finding moments of freedom from ableism in nonhuman nature amongst people living with varying forms and severities of sight impairment. While recognising the many theoretical and ideological shifts that have occurred around the concept of nature, and the nature-society dualism (Bell et al., 2018), in this paper I adopt a broad interpretation of 'nature', starting from participants' own conceptions and descriptions. Participants situated humans as part of nature to varying degrees, and shared examples of encounters with both nature 'out there' (for example, in countryside, coastal and woodland settings) and nature closer to home (be it birdlife in gardens, parks or simply feeling the elements upon stepping outside the front door). Characterising these moments of freedom from ableism in nature as social freedoms, mobile freedoms and exploratory freedoms, I also seek to demonstrate when and how such freedoms are curtailed by pervasive stereotypes of sight impairment, independence and accessibility, and opportunities to counter this in future policy and practice.

\section{Methodological approach}

The findings presented below are drawn from an in-depth qualitative study examining how people with varying forms and severities of sight impairment in the UK have come to experience a sense of wellbeing (or otherwise) with diverse types of nature during the life 
course. Recognising people's myriad interpretations and conceptions of nature (Castree, 2014), the study was guided by four overarching research questions: (a) What is 'nature' to people living with diverse forms of sight impairment? (b) What types of encounter promote a sense of wellbeing and meaningful connection with nature? (c) To what extent, if at all, do people feel impaired in varied forms of nature and how might this change over time? (d) What could we learn from these ways of sensing and making sense of nature? These questions were explored using an in-depth, qualitative interpretive methodology, encouraging people to describe their experiences and understandings in their own terms, facilitating valuable insights into the complexities of life with visual impairment (Duckett and Pratt, 2001). Ethical approval for the study was secured from the University of Exeter Medical School Research Ethics Committee (Approval Reference Dec16/B/108).

A broad approach to health and wellbeing was adopted throughout the study, moving beyond narrowly defined biomedical conceptions of health that problematically focus on 'cure' as the 'restoration of health' (Clare, 2017a: 57), and countering the growing tendency to present 'health as much simpler than it actually is' (Wolf, 2010: 84). Recognising both health and wellbeing as complex, multidimensional and relational (Atkinson, 2013), the study sought to explore and situate participants' own sense of health and wellbeing in their everyday and whole lives, asking 'about their experiences, feelings and interactions with the world, and their perceptions of those experiences' (Dinnie et al., 2013: 104). In this paper, I focus on a subset of those experiences that identified within the accounts of nearly all participants; opportunities to experience moments of freedom in some form, be it sensations of freedom in the body (contributing to moments of peace or pleasure), freedom 
to make one's own life choices (autonomy), freedom to forge meaningful relationships (positive relatedness), and to push oneself, learn and explore (personal growth).

Two overlapping phases of fieldwork were conducted between February and December 2017. Phase 1 involved participating in sight loss awareness and sighted guiding training, before actively volunteering with a range of activity groups around the UK, including both indoor and outdoor groups designed to bring together sight impaired individuals with common leisure interests. As a researcher without sight impairment, joining in with over 15 full day activity sessions provided a valuable opportunity to recognise and confront some of my own misperceptions and assumptions about sight impairment. During these activities, I became keenly aware of the diverse ways in which people described and labelled their embodied forms of visual perception - from people self-identifying as 'registered blind', 'visually impaired', 'vision impaired', 'sight impaired', 'partially sighted' to those adopting the dual meaning of the 'VIP' acronym, 'Visually Impaired Person' and 'Very Important Person'. Early discussions prior to and during Phase 1 suggested 'sight impairment' might be a useful umbrella term to use (avoiding some of the negative stereotypes and misperceptions of 'blindness' described by Bolt, 2016, as well as unhelpful connotations of impaired insight associated with the term 'vision'). Whilst I therefore use 'sight impairment' as an umbrella term here for consistency, care was taken to adopt each participant's preferred language throughout the fieldwork.

Phase 2 involved in-depth one-to-one interviews with 31 people recruited from around the country with the assistance of the Royal National Institute for the Blind 'RNIB Connect' magazine, the Thomas Pocklington Trust, Blind Veterans, the Macular Society, and several local and regional sight loss organisations who offered to raise awareness of the study 
through their member networks. Purposive sampling allowed 'information rich' views to be contributed by individuals at different life stages and with diverse forms and severities of sight impairment, rather than focusing on the 'typical' or average case (Flyvbjerg, 2006). The sample included: 15 men, 16 women; aging from mid-20s to mid-80s; living in rural areas, towns and cities; with varied conditions affecting people's field and clarity of vision, including colour, light, depth and object perception (glaucoma, age-related macular degeneration, retinitis pigmentosa, diabetic retinopathy, congenital cataracts, retinopathy of prematurity, Leber's Congenital Amaurosis, Leber's Hereditory Optic Neuropathy, coloboma, retinal detachment, rod-cone dystrophy, and sight loss caused by accident and/or brain injury). Of the 31 participants, 28 were registered either severely sight impaired or sight impaired, with the remaining three contemplating registration. Fifteen participants were born with at least one eye condition, including 12 people who had experienced further sight changes later in life. Whilst I use these categories here to introduce the study sample, I remain wary of locating people on overly rigid 'diagnostic maps' (Nocella, 2017: 151), and recognise the importance of engaging with intersectionality and the fluidity of people's identities to fully understand people's experiences of freedom (or otherwise) with nature. As noted by Michalko (1999: 107):

\footnotetext{
"Blindness is not simply the negation of sight: it is a way of sensing the world and a way of being in the world that is influenced by such social conditions as place and time of birth, age of onset of blindness, social class, gender, race, and all the individual particularities that each of us has".
} 
Although I endeavour to attend to these intersections here by engaging with participants' 'specific, many layered lives' (Morales, 2015: xii), an important limitation in the sample is its relative homogeneity in terms of race and ethnicity, with 29 participants identifying as White British and two as Asian British. This limitation should be addressed in future work, particularly given the growing body of literature highlighting the detrimental impacts of racial exclusion on people's experiences of nature in varied forms and settings (Bell et al., 2018; Crang and Tolia-Kelly, 2010; Byrne, 2012).

All 31 participants took part in an initial narrative interview (Riessman, 2008), lasting from one to three hours, examining what nature is to them, how they sense, experience and negotiate different types of nature in the context of their day-to-day lives, changes through key life transitions and 'chapters' of their lives, and how they feel about existing efforts to support more inclusive multisensory nature encounters, based on their experiences both within the UK and beyond. These narrative interviews offered valuable insights into how people's wider life circumstances had influenced their nature conceptions, experiences and embodiments, framing impairment as just one of many fluid subject positions and identities that shape people's nature experiences. As someone born with an impairment (albeit an invisible impairment with greater influence on my longer-term life choices than my immediate opportunities to participate in everyday life), I am keenly aware of the value of such life course approaches in facilitating deeper understandings of how, when and why impairment - situated within the broader web of social relations we enter into - can influence lived experience.

Twenty-five of the 31 participants took part in a second 'go-along' interview (Carpiano, 2009) within a setting they valued for encountering nature in their everyday lives. 
These 'in situ' interviews created opportunities 'to witness an array of embodied and emotional practices as they are experienced and performed by those involved' (Anderson and Jones, 2009: 299), including a range of subtle strategies used by participants to negotiate varied forms of nature. Interview locations included participant gardens, local residential road/path networks, urban parks, woodland, coastal and countryside areas, with interviews lasting from twenty minutes to four hours according to participant preference. Participants indicated how, if at all, they would like to be guided, be it via the traditional method of holding just above the elbow for support, or by holding either end of a walking pole/rope, or walking independently following a sound signal and listening out for verbal instructions pertaining to oncoming obstacles or changes in direction. In practice, guiding preferences varied through the course of each interview, depending on the demands imposed by the terrain, the weather, the presence of other people and traffic.

Each interview was recorded and transcribed verbatim, with transcripts annotated to capture any expressions of emotion such as pauses, sighs, frustration, laughter, tears, hesitation or changes in tone. Organising the data using Nvivo 10 (qualitative data management software), the Phase 1 and 2 field diary entries and Phase 2 interview transcripts were subject to in-depth inductive analyses. Multiple lenses (macro, meso, micro, interactional, temporal and spatial) were applied to situate participants' nature experiences in the personal, social, cultural and physical contexts of their everyday and whole lives (Pamphilon, 1999). Through this analytical process, descriptions of opportunities to experience a sense of freedom with nature - and human/nonhuman encounters that supported or compromised such sensations - recurred throughout the interviews. This paper examines such opportunities, focusing on the varied benefits of - and challenges 
faced by participants in - seeking out a range of freedoms from ableism with nature, characterised as social freedoms, mobile freedoms and exploratory freedoms. In doing so, it calls for a more emancipatory body politics to ensure such freedoms are not undermined by inappropriate or ill-considered ableist responses to sight impairment and inclusivity in nonhuman nature.

\section{Findings and discussion}

While the opportunity to experience a sense of freedom with nature was apparent across the narratives of nearly all the study participants, I focus here on the detailed stories of three participants to demonstrate how and why varied forms of nature interaction became important at different life stages in nurturing moments of freedom from the many experiences of ableism encountered in other aspects of everyday life. To do so, I characterise three types of freedom: social freedoms, mobile freedoms, and exploratory freedoms. Although examined in turn for analytical purposes, their interdependence in shaping broader moments of freedom from ableism is apparent throughout.

\section{Social freedoms}

The first participant I would like to introduce is Abbie. At the time of the study, Abbie was in her 40s, and had experienced the gradual onset of a progressive sight condition since her 20s. She lived alone in a rural English town, but grew up as a white expatriate in Africa, with her childhood split between school holidays spent with her family back home and term time at an English boarding school. For Abbie, nature had always been something to respect, something awe inspiring and beautiful but also risky: 
"I was out in Africa, and that was wonderful in terms of nature, you know, nature just came in all the time! You're constantly going 'Get out nature!' I had cats that would bring in snakes and things, and you'd be like 'Oh what is under the carpet now?!' But also, because I grew up there, I was so lucky as a kid because then it was very underdeveloped and there were wonderful game parks, that they still have now but we were able to access them really easily, you know? Not easily, it was quite dangerous, but as a family we would take off and go for days and days camping in the bush... and I guess that also really affected how I felt about English nature because I only saw it as a school thing, and I wouldn't see it through the summer. So it was kind of cold and dark, or cold and grey, or just grey. And I always associated light and colour and animals, free animals and vegetation and insects with Africa... England is terribly safe in terms of its - you know, you get run down by bullocks, maybe but (laughs), in terms of its wildlife, you're not really going to get savaged by a badger! And so I didn't really connect with England and nature until l'd moved here properly and my sight was really going".

In this quote, Abbie highlights how her childhood in Africa had really shaped her conceptions of what nature is, and left her with somewhat ambiguous feelings about the nature in England in comparison to the vibrant, albeit riskier, nature that was very much part of her everyday life back in Africa. Later in the interview, however, she explained that the 
detrimental attitudes she was encountering in response to her sight changing in Africa was a key driving force in her decision to move back to the UK:

"And then my sight deteriorated and I came back to the UK... because it was too dangerous. I couldn't drive anymore and I was working in some quite difficult areas in terms of some of the people I was working with. So it wasn't safe for me to be living on my own and in that situation... and people just couldn't comprehend it. And yet, you know, now there's a lot more blindness there, because of HIV there's a particular cancer... so it's just one of those conditions that has become prevalent because of the amount of people with infections. But, you know, that looks like a problem, and very rarely would you have somebody who was visually impaired who didn't have something obviously wrong with their eyesight. So the idea that you would still look sighted was just too problematic. It was witchcraft, witchcraft... I got physically attacked twice... some guy thinking it was witchcraft because, you know, white people can't go blind and, you know, you've got sight during the day and you're only visually impaired at night... it was really horrible, really really difficult".

The highly detrimental social encounters stemming from the lack of awareness of the plurality of sight impairment and the racial prevalence of different conditions in Abbie's home country within Africa, alongside the physical constraints she was experiencing in her career through no longer being able to drive, catalysed the decision to move to the UK, based on the hope that such stereotypes and ableist attitudes may be less prevalent. Whilst 
this was the case to some extent, Abbie still experienced a number of challenges in getting out into the nature around her, and expressed frustration at the lack of support for that despite the growing awareness that time spent with nature can be beneficial for health and wellbeing (Frumkin et al., 2017):

"I think nature has become more important to me in some ways, now that I, I find it harder to get to it... because it's unnecessary that it's harder to get to, so it feels like an unnecessary separation. And an unfair separation... It's like, it should be more important to get us out into the wilderness, because we know that it's beneficial for health and happiness. So it should be more important that we get there, and yet you know that it's not. And that is really frustrating, because I know that I will feel better when I get outside. But it's just difficult to get outside, sometimes" (Abbie).

In this quote, Abbie highlights a deep sense of frustration in not being able to access nature and the implications this has for her health and wellbeing. She explains that she 'knows' she will feel better through getting outside and into the 'wilderness' near home (fields and woodland) but notes that "it's just difficult to get outside sometimes". Many participants explained how these challenges are magnified when access has not been considered in more rural areas, and at particular times of year when light and weather conditions undermine opportunities to use residual vision and hearing to navigate otherwise familiar nature settings (a more detailed discussion of the weather and sight impairment is provided in Bell et al., 2019). Nature is often lauded as an affordable setting for leisure, health and wellbeing 
(Harrington, 2015; O’Brien and Morris, 2014); and for those living in towns or cities with accessible nature on the doorstep, this may be the case when sensitively designed and managed. However, the freedom to choose more peaceful, remote or rural nature encounters has been curtailed for many people living with sight impairment in the wake of austerity-driven cuts to public transport services; an issue catalysing much frustration amongst study participants living in more rural areas.

Throughout Abbie's accounts, she expressed feelings of loss for the African nature and visual nature scenes she could no longer engage with, but also feelings of gratitude for the relative safety of the English nature that she used to dismiss as 'dark and grey' as a child:

"I've got this idea of how things look. I can't see colour in the same way, anymore. And, as I say, I can only see piecemeal. So, in my head, the kind of romance of the big vista, or the incredible view, or the amazing sky, that's something to be written, not something to be seen anymore... and I grieve for that a lot, I grieve for, sometimes for not being able to see the bluebells in the same way, or when you go into woods here, the changing colours. I can appreciate beauty when I catch it, of course, and in the smallest things and the biggest things. But it's harder to catch, and it's always with that melancholy of how long, or how much longer? ... But it is really interesting how one changes. I mean, thinking about this place and how good it's been to me and how beautiful it is - I mean, I know it's also very isolating, and it's not very diverse. But, you know, these things change ... It's that kind of, you know, acknowledging change, 
not as a (sighs), it's not cutting you off, it's just pushing you in a different direction".

As noted by Kafer (2017: 218), 'loss is a topic disabled people are typically reluctant to discuss, and for good reason', since disability is all too often solely equated with loss, bitterness and tragedy. However, it is also important to recognise how loss and grief features for people who lose their sight (Murray et al., 2010; Nyman et al., 2012), exploring how different people 'reckon' with loss and find a way through it. Abbie described various ways in which she had come to work through her sense of loss, including the process of writing, but also coming to appreciate new forms of nature and alternative ways of interacting with it. During our go-along interview, Abbie navigated us round an eight mile countryside walk that she had spent several months memorising through trial and error. She had used a combination of a somewhat out-dated route description in a local walks book, a long cane for stability, and repeated efforts to tailor the route directions using clear visible, audible and tactile landmarks she could identify (with someone at the end of the phone in case of getting lost and the light fading). Taking the time to do this, despite the risks (even in English nature), was important to Abbie in enabling her to access moments of peace and embodied freedom that she struggled to find within more built-up environments:

\footnotetext{
"For me, the wonderful thing about nature is when I can step to a place where I can be free in my body and be quiet, but just with different noise, with natural well I say 'natural' noise, but you know - birdsong, trees, being able to hear a river or the sound of a river nearby, different smells, it kind of makes me
} 
straighten up and feel less vulnerable, funnily enough... whereas, the kind of concrete and scaffolding and crowds and cars, lorries going past, people revving, all that tension, people, you know, emotional tension as well, people yelling at their kids, or calling out after each other or, you know, car doors slamming... it's very wearing... so just to have a time when you can just be physical, walking, but really free in the body, to not have that kind of constant anxiety about what's going to happen next... And the sensation of walking, it always unkinks my brain... it's just that physical thing of moving forward and moving through an environment that's quiet and, and unpeopled. The unpeopled thing is really important".

In this extract, Abbie prioritises 'unpeopled' interactions with nature, explaining how the auditory, kinaesthetic and affective dynamics of busy social configurations often challenged her embodied boundaries, foreclosing opportunities to be free of anxiety or 'free' in her body. During the go-along interview, she described a risky encounter with "a wall of breathing bullock" while out walking her eight-mile loop. She explained, however, that sometimes "it's more frightening to have to deal with your visual impairment to other humans" than it is to "tackle a herd of bullocks". Since other people cannot see through her eyes, they cannot seem to understand that her sight changes all the time - with the light, the weather, with stress - and that this influences the support she needs; people then either forget completely or become "hyper aware and too controlling", thereby removing her sense of freedom through walking altogether. 
In sharing extracts of Abbie's narrative in this way, I have sought to demonstrate how forms of ableism intersect with people's wider life circumstances in shaping how and why different social freedoms become more or less important in nonhuman nature at different stages of the life course: freedom from disabling social attitudes based on narrow conceptions of sight impairment and how it presents; freedom from disabling environments that generate feelings of anxiety and tension; and freedom from overly protective social encounters and 'social relations of differencing' (Parr, 2008: 80) that fail to see past impairment to recognise and respect people's individual skills and abilities. I have also aimed to demonstrate how 'different personal histories come tangling into our collective one' (Clare, 2015: 117) in shaping what people value in nature, and the risks perceived therein.

\section{Mobile freedoms}

The second participant I would like to introduce is Eve. At the time of the study, Eve was in her 60s, and was born with a sight condition. Efforts to treat this condition catalysed the onset of an additional, progressive sight condition, leaving Eve with about $10 \%$ of her sight as an adult. Although Eve grew up in the countryside, she lived with her husband and children in an English city, trading in her dreams of 'living the rural idyll' for the relative independence she gained by living in an urban environment:

"At the same time as wanting to live the rural idyll, I have to accept that I need independence and I need to be able to get where I need to get on my own ... I know if I buried myself in the country with a sort of minimal bus service, although 
I might have a certain amount of freedom to roam, and perhaps a bigger garden to enjoy, it would limit my freedoms in other ways".

Eve described a difficult childhood, losing her mother as a toddler and being sent away soon after (along with her older sister) to a specialist boarding school for children with sight impairment, where she stayed for nearly 17 years. Eve described the boarding school as providing a somewhat cloistered existence segregated from the 'sighted world' and devoid of love and care. The role of the school field as both a place of freedom and torment was apparent, both within her words and in the highly visceral emotions that these memories evoked for her during the interview:

"Living in it [nature] as a small child, having the freedom to be out in it, without adults around and to explore it on my own terms, I will always be grateful for that. And I think it was those early years that really made it essential to me. And I think helped me to recognise that this is the environment that I like to be in best. This is where I feel most at, at peace, most secure, most stress free... Once we'd gone to school, it was perhaps more difficult. It was a very cloistered existence at school. Not that we were completely devoid of access to nature, because there was THE field (laughs)... it was a huge field. The school's actually built on, what was an army barracks... It was very basic and it was devoid of, well, comfort and, if I'm absolutely frank, it was devoid of love (pause)... And I didn't really know quite why I'd been sent away, why we weren't at home anymore... I didn't realise that I was sight impaired, I wasn't really aware that I was different from anybody 
else ... And in this - what to begin with was a horrible place - nature fitting into that, it was really the opportunities to go up the field... the field was a place where you could actually go and escape, and again, be on your own terms. It was huge and it had things to play on and play in. And it had space, and it had trees. And it was a good place to just go and let off steam, I suppose, to run around as much as you liked. It had a running track. And when I was older, and just so desperate to break out and break free, it was my salvation... I used to get up, and I used to go for a run on the running track. And I used to love going out when the dew was still on the grass, and nobody else was up and about, on a summer morning, and just run barefoot. (pause) Mmm, that was very important (long pause, chokes up). It's quite odd talking about all this (pauses interview)... I think it's because (pauses, choked up), I don't talk about it very much, probably with good reasons (laughing and crying). It's (pause), obviously quite emotional. I don't really know why (chokes up)... But having the freedom to do that was really important (pauses). And we used to keep rabbits. That was the concession to the need for pets. (laughs) And so I used to love looking after rabbits, just holding them and looking after their wellbeing... just that sense of, having something living to cuddle (chokes up)... sorry I'll get a grip in a minute (laughs)... Because I have to say that the field also became a place of torment, because we had to go up there in all weathers. Whether it was raining, whether it was snow on the ground, you'd be up there for two hours at a time in the snow... It's one of the reasons why the rabbits were such a great thing, because if you looked after the rabbits, you didn't have to go up the field" 
In this extract, Eve demonstrates the highly limited sense of freedom she experienced through the first 20 years of her life before sight impaired children were able and encouraged to join mainstream schooling in the UK. Eve's cherishing of the school rabbits as an otherwise elusive source of love and warmth (literal and metaphorical) in this restrictive, institutionalised environment is perhaps not surprising, particularly while also trying to process the grief of losing her mother and coming to terms with 'being sight impaired'.

Such experiences clearly shaped Eve's priorities regarding opportunities for more 'inclusionary socio-natural relations' (Parr, 2008: 87) giving her the freedom to move, and move safely, and importantly the freedom to choose how and when she engaged with nature. These freedoms were very much lacking for most of her childhood and early adulthood as a result of ableist societal attitudes regarding the educational needs of children with sight impairment at the time. Eve expressed particular frustration at the common misperception that creating separate sensory gardens (gardens that were originally somewhat problematically called 'gardens for the blind') in more expansive nature settings was sufficient in promoting disabled access:

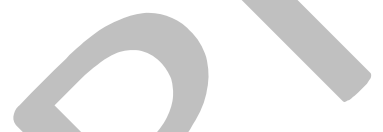
"To be quite honest, most sight impaired people are completely bored by the sensory garden... People have a go at playing with it but it very often isn't particularly sensorially rich. You know, people think, oh you fill it with plants which have got lots of movement, so that the air moving through them provides lots of sounds, and lots of different textures and smells, and so on. But to some extent, once you've been in it, you've been in it. It's being able to move that I 
think is most enriching, and being able to move safely... One of the things that I like about the park near here is, it's got a number of different types of environments. And I think that's what needs to be considered. So you've got somewhere that is, you know, sort of cool and dark and damp. But you've also got somewhere that is high and light and airy, and somewhere where you can hear water, but also somewhere where you've got really lofty trees. So it's variety really"

Eve, and several other participants, explained how being limited to short sensory trails or small sensory gardens failed to accommodate the kinaesthetic sense, while also inadvertently reproducing segregated nature experiences. In doing so, such initiatives frame people first and foremost as individuals with disability, rather than idiosyncratic individuals with diverse nature interests, knowledges and skills (Bell, 2019). While more expansive nature settings - such as moorlands or open countryside - were often described as too broad and too wide to navigate independently, many participants appreciated more manageable yet varied parkland or downland settings, with legible, even tracks to 'swing' along freely. Several participants also described and demonstrated (during the go-along interviews) a range of techniques developed to maximise these opportunities for mobile freedoms. These included: walking behind a fully sighted walker, each holding either end of a walking pole to allow greater individual freedom of movement than the more traditional guiding technique of holding an elbow; following the sound of bells attached to a walking partner's rucksack, while walking with two poles both for stability and to 'read' the ground beneath them; walking the same route repeatedly with a long cane, each time receiving less 
description or direction from a walking partner, gradually building sufficient familiarity with tactile/auditory landmarks en route to walk the route alone over time; or - as demonstrated by Abbie - memorising a detailed route description and testing out small sections of it independently over time until confident enough to piece together the whole route within the hours of daylight. The sense of achievement gained through tackling these routes - and learning to negotiate varied risks along the way - was palpable during the go-along interviews, with many participants describing their techniques at length and recalling particular moments of euphoria en route where they had first reached a particular milestone or discovered a useful landmark. As one participant in his 50s, Seth, commented:

"That's the nice thing because you sort of feel people need to go, oh I don't know, climbing the Himalayas or doing some massive like Land's End to John O'Groats trip, or something. But for me, just walking a mile from my house on my own and back, I can get that same thrill".

Reflecting Gattrell's (2013) concept of 'therapeutic mobilities' and Foley's (2017) notion of 'therapeutic accretion', the analyses presented here demonstrate the potential for moments of embodied mobile freedom to unfold in physical nature settings and/or social circumstances where inclusive site design, management and interpretation combine to facilitate fluidity of movement, sensation and feeling in unison (Small, 2015). Our study participants, like Eve, highlighted how mobile freedoms are as much about the sensations the whole body tactility - of moving with and exploring diverse forms and habitats in nature 
as they are about getting from $A$ to $B$, finding opportunities to cultivate the skills to do so with dignity and ease.

\section{Exploratory freedoms}

The third participant I would like to introduce is Brett. At the time of the study, Brett was in his 40s, and was born with a progressive congenital sight condition. Living alone in a large English city, Brett cherished opportunities to explore new terrains in nature, both within and beyond the city, above and below ground. Reflecting on his recent caving experiences, for example, he described his fascination for all the geological formations and rivers running underground, and the excitement of "experiencing something completely different that is totally outside of your normal range of experiences". Cultivating the skills required to negotiate these nature encounters was integral to mobilising these exploratory freedoms. Such opportunities had become particularly important to Brett in recent years, after having to retire from a much-valued career following the onset of new sight complications in his late 30s:

"It was a very big change for me giving up my work. And going from working, whatever it was, ten hours a day to working zero hours a day ... For me, there was a big loss of identity... And as a disabled person you carry quite a lot of baggage, anyway, from society. You know, you're disabled so you have all those stereotypes, you're either a 'hero' or a 'scrounger' ... But a lot of that baggage can be offset against an alternative identity, if you have a strong one. And for me my career helped me to kind of offset all that stuff ... and I think it wouldn't be 
going too far to say that, having found the opportunity to get involved in these outdoor activities, not only did it give me a focus, but it's also helped reform my own identity. It doesn't replace the one that l've lost... but in my own mind, at least, I find that being involved in lots of outdoor activities, and having a sense of personal achievement when I do some increasingly difficult things, that has made me feel a lot better about myself".

For Brett, opportunities to learn the techniques and skills required to negotiate varied risks in nature were central to his feelings of freedom; offsetting the detrimental, ableist stereotypes that often come with disability, and providing a 'means of emplacing oneself outside the flow of everyday life' (Foley, 2017: 48), while exploring new - often uncomfortable - terrains. In this way, and with appropriate support, Brett was able to develop enhanced 'situational awareness' (Rickard, 2014) within riskier terrains, taking time to (re)build an embodied sense of competence:

"I mean, you can't say it's comfortable to do outdoor activities. You know, you're often wet, cold, tired, you often hurt yourself, there is a degree of risk. But it was all of that, it was all of the contrasts between those things and normal life that, I think, appealed to me. And I think appeal to a lot of people who have the chance to do it. But the sad thing is, not that many disabled people do, certainly not that many visually impaired people do, and I think one of the biggest barriers is the insufficient numbers of people who-able-bodied people-who have the experience and the appetite to take the risk... appreciating risk, sensible risk, and 
not over perceiving risk, but having a realistic appreciation of risk. And having the ability and the skills to manage that risk... And the real knack, I think, of a true professional is to be able to make those very fine judgements, but to do it with grace and ease. And without the participants necessarily feeling that they're always balancing that risk... because if you're being made to feel that other people are constantly balancing risk for you, then it entirely detracts from doing that activity because then the sense of achievement and freedom that you have, is no longer there"

In this quote, Brett calls for more 'able bodied people' (that is, skilled outdoor activity instructors) to support people in mobilising exploratory freedoms with 'riskier' natures. Brett's account is consistent with earlier studies highlighting how the preoccupations of many outdoor service providers with risk management, informed by inflated notions of risk and ableist discourses of vulnerability and impairment, have progressively undermined opportunities for people with impairment (sight impairment or otherwise) to develop the skills required to climb, cave or paddle with 'wilder' natures (Tregaskis, 2004; Burns et al., 2013).

Rather than reproducing so-called 'supercrip' narratives of independently 'overcoming' impairment to 'conquer' the mountains, Brett explains how his sense of achievement and freedom to explore these more challenging terrains in nature necessarily relies on professionals with a realistic appreciation of risk, and the appetite, skills and confidence to support positive risk taking in a dignified, constructive way. In this way, he described such experiences as a collaborative achievement and a mutually rewarding, shared experience: 
"One of the things that makes the experiences I have valuable, and I suppose one of the reasons I keep going back, is that when we do them, we do them as a group of friends. And I think of the lead instructor of most of the stuff I do, and the lead instructor of the sailing, I think of those people as friends. And we relate as friends, even though I am more than aware that they have a professional role, and that they're there to ensure my safety and stuff. But in some ways, I don't see that as any different from, for example, if I was in a local climbing club where you would have experienced people, or a local caving club, or a local canoeing club. It has a lot of the attributes of a club, you know. We meet regularly, we get on, you know, we, we like each other!"

These quotes raise important questions regarding the notion of 'independence' and 'independent access' to nature. As articulated by Brett in the extract below, when getting out into nature, everyone - impaired or otherwise - is dependent on various levels of human and nonhuman intervention; be it in terms of the paths and tracks built to guide people in and through parks, woodlands, the countryside or further afield, the maps produced to support orientation and way-finding, the steps built to take people down from cliff tops to beaches, or the intensive periods of skills training that teach people how to appraise and manage risk when engaging in skilled activities like climbing, caving, sailing, kayaking: 
"I know that I can't do these activities without the support of others. And yet that doesn't take away from my own achievement in participating in them. But it's an interesting philosophical discussion, which I've had several times. It's kind of like, well on the one hand I totally recognise that if it wasn't for the goodwill of others, I wouldn't be achieving these things, because I couldn't just go and buy a boat and go and sail it, or I couldn't just go and explore a cave. That would be extremely foolhardy and I wouldn't do it. So, necessarily my disability means I do rely on the goodwill and professionalism of others... And yet, when I am sailing with them, and I am doing a sail change, even though I know perfectly well they could do the sail change, and I know perfectly well that they're there to facilitate me doing the sail change, as long as they are kind of part of the process of facilitating me in doing it, I still have that sense of freedom and achievement of having done it myself... and I suppose, I suppose in some ways, we all rely on others, don't we?"

As noted by Kafer (2017: 216), the failure to recognise these broader forms of dependency in society 'suggests an act of ableist forgetting'. All bodies have 'needs', be it shelter, water, food, emotional support; 'bodies are "lived" in social interconnection and interdependency: we are all dependent on others' (Thomas, 2007: 87). Yet such mutual interdependencies are often eclipsed in contemporary western societies by our growing preoccupation and valorisation of self-sufficiency, with certain forms of dependency vilified over others. Recognising this, a more emancipatory body politics is needed that challenges pervasive ableist assumptions, instead recognising, respecting and celebrating human and nonhuman 
interdependence. As noted by Kafer (2017: 226), 'recognising our interdependence makes room for a range of experiences of human and nonhuman nature, disrupting the ableist ideology that everyone interacts with nature in the same way'. Only by nurturing an 'ethic of openness' (Ray, 2017: 60), not just to nature but to embodied and cultural diversity, can people's social, mobile and exploratory freedoms be fully tapped; accepting 'nature' in its fullest sense and encouraging the multiplicity of ways of sensing, being and moving through the world.

\section{Concluding remarks}

Grounded in the social-relational model of impairment and disability (Thomas, 2007), this paper has examined the ableist assumptions that underpin popular discourses of nature and independent nature access, and foregrounded opportunities to experience freedom from ableism with nature, characterised as social, mobile and exploratory freedoms. In doing so, it seeks to make room for a range of experiences of human and non-human nature, and fold issues of social justice (Clare, 2017a: 89) into the growing momentum to connect people with nature in the name of health and wellbeing.

The challenges and benefits of finding social freedoms were apparent across all participant accounts, with many highlighting the complex role of social dynamics in shaping opportunities to experience a sense of embodied freedom through their nonhuman nature experiences - be it close to home, or further afield in the countryside, up a mountain or at sea. Shared experiences with people who appreciate the dignity of risk often enhanced such opportunities, offering valued companionship, facilitating familiarisation with local terrains, cultivating the skills and competences required to take on a mountain, cave or rock face, or 
simply offering support, orientation clues and encouragement. However, crowding, noise and negative ableist attitudes encountered in other social contexts were flagged as particularly detrimental to moments of embodied freedom. The latter may stem from deeprooted - often pre-reflective - prejudices regarding the worth and value of so-called 'impaired' bodies within society (Reeve, 2002); prejudices that create 'fixed and othering boundaries' (Parr and Butler, 1999: 9) that fail to 'recognise the fluidity and transformative nature of bodies in space' (Imrie, 1999: 40) and over time.

Mobile and exploratory freedoms were accessed when the physical fabric of an environment and its social qualities coalesce to offer a sense of embodied relief from day-today constraints, emotional tensions and unhelpful social stereotypes. For some, this occurred through pleasurable immersion in the garden or while 'swinging' along relatively even, legible trails within urban park, woodland, coastal or countryside settings. For others, it emerged through developing shared, embodied strategies to tackle 'riskier' terrains, including rocky paths, mountains, moorlands and caves. Notably, such experiences are not dissimilar to those identified in the wider literature on people's experiences of health and wellbeing in nature (e.g. Dinnie et al., 2013; Foley, 2017; Brown, 2017). However, opportunities for these experiences, momentary or otherwise, were much harder to find due to the ableist conceptions of risk and vulnerability often encountered with sight impairment. Many participants described an incremental process of locating such moments over time, allowing themselves to build confidence in different situations; starting with challenges just outside the front door, and gradually working up to more unpredictable terrains and environmental conditions, cultivating new bodily know-how (sensory knowledges), re- 
building trust in the body, and living life with a renewed sense of embodied agency (Burns et al., 2013).

These findings highlight the need for more critical approaches to the promotion of 'nature' as a resource for health and wellbeing through the life course; nature can be many things to many different people. If we are to support more inclusive opportunities to experience nature in its different forms, we need to give people the freedom to be, explore and move with(in) natures that resonate in the context of their everyday lives, regardless of their embodied needs and priorities i.e. the freedom to choose. For some, such needs may be met through inclusive design efforts (see Bell, 2018), ensuring accessible and engaging path networks, multisensory site interpretation and inclusive events programming (Sensory Trust, 2017). Importantly, such efforts need to extend to the surrounding areas to ensure people can access such settings safely, through connected pavements, trails and effective public transport links. Modifications to the physical fabric of other settings can be more challenging, for example, mountain summits and steep cliff faces, or areas with designated conservation value. However, people may still be able to explore such terrains safely over time through cultivating new skills and situational awareness with appropriate, personcentred support. Such support needs to go beyond the provision of one-off 'taster' days to allow people to build the familiarity, confidence and genuine skills required to engage in positive risk taking, allowing them to feel 'in place' and welcome within such settings over time. As noted in a recent report by the Sensory Trust in collaboration with Natural Resources Wales (2017: 9), 'equality isn't about treating everyone the same, it is about respecting differences and finding ways to make everyone feel welcome and supported. At 
its root, what is most needed is a positive, open attitude and a welcoming approach combined with good communication and understanding'.

Nurturing such opportunities requires more fundamental societal transformations towards an emancipatory body politics (Chouinard, 1999) that challenges ableist assumptions and discourses, embracing all bodies as multidimensional and dynamic. Such a politics could halt and reverse the growing tendency to valorise 'self sufficiency' and independence over trust, care and embodied respect. The more we address the ableist norms and designs that permeate our world - built, socio-natural or otherwise - the more likely it is that we can all live freely in a world where embodied diversity is both 'common and unremarkable' (Clare, 2017a: 167).

\section{Acknowledgements}

Many thanks go to all the study participants for sharing their experiences; to the many environmental and sight loss sector organisations who have taken the time to shape the study; to the Economic and Social Research Council for funding the Sensing Nature study through their Future Research Leaders fellowship scheme; and to the three anonymous peer reviewers for offering such constructive, insightful feedback on earlier versions of this paper.

\section{Data Accessibility}

Due to ethical concerns of maintaining participant confidentiality, the research data supporting this publication are not publicly available. 


\section{References}

Alaimo S (2017) Foreword. In: Ray SJ and Sibara J (eds) Disability Studies and the Environmental Humanities. Toward an Eco-Crip Theory. Nebraska: Board of Regents of the University of Nebraska, pp. ix-xvi.

Anderson J and Jones K (2009) The difference that place makes to methodology: uncovering the 'lived space' of young people's spatial practices. Children's Geographies 7: 291-303.

Atkinson S (2013) Beyond Components of Wellbeing: The Effects of Relational and Situated Assemblage. Topoi 32: 137-144.

Beauchamp-Pryor K (2011) Impairment, cure and identity: 'where do I fit in?' Disability \& Society 26, 5-17.

Bell SL (2018) Sensing Nature: Designing urban greenspace with sight impairment in mind. A report produced in collaboration with the Sensory Trust [online]. Available at: www.sensingnature.com [Accessed $16^{\text {th }}$ November 2018].

Bell SL, Leyshon C, Foley R and Kearns RA (2018) The "healthy dose" of nature: A cautionary tale. Geography Compass, doi: 10.1111/gec3.12415. 
Bell SL, Leyshon C and Phoenix C (2019) Negotiating nature's weather worlds in the context of life with sight impairment. Transactions of the Institute of British Geographers, doi: 10.1111/tran.12285.

Bell SL (In Press) Sensing Nature: Unravelling metanarratives of nature and blindness. In: Atkinson S and Hunt R (eds) Geohumanities and Health. Springer Global Perspectives on Health Geography, Chapter 6.

Bolt D (2016) The Metanarrative of Blindness. A re-reading of twentieth-century Anglophone writing. Michigan: The University of Michigan Press.

Brown KM (2017) The haptic pleasures of ground-feel: The role of textured terrain in motivating regular exercise. Health and Place 46: 307-314.

Burns N, Paterson K and Watson N (2009) An inclusive outdoors? Disabled people's experiences of countryside leisure services. Leisure Studies 28(4): 403-419.

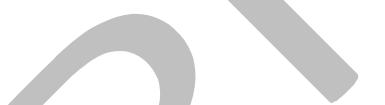

Burns N, Watson N and Paterson K (2013) Risky bodies in risky spaces: disabled people's pursuit of outdoor leisure. Disability and Society 28(8): 1059-1073.

Butler R and Bowlby S (1997) Bodies and spaces: an exploration of disabled people's experiences of public spaces. Environment and Planning D: Society and Space 14: 411-433. 
Byrne J (2012) When green is White: The cultural politics of race, nature and social exclusion in a Los Angeles urban national park. Geoforum 43: 595-611.

Carpiano R (2009). Come take a walk with me: the 'Go-Along' interview as a novel method for studying the implications of place for health and wellbeing. Health and Place 15: 263272.

Castree N (2014) Making sense of nature. Abingdon: Routledge.

Chouinard V (1999) Body politics: disabled women's activism in Canada and beyond. In: Butler R and Parr H (eds) Mind and Body Spaces: geographies of illness, impairment and disability. Abingdon: Routledge, pp. 269-294.

Clare E (2015) Exile and Pride: Disability, Queerness, and Liberation. Durham: Duke University Press.

Clare E (2017a) Brilliant Imperfection: Grappling with Cure. Durham: Duke University Press.

Clare E (2017b) Notes on Natural Worlds, Disabled Bodies, and Politics of Cure. In: Ray SJ and Sibara J (eds) Disability Studies and the Environmental Humanities. Toward an Eco-Crip Theory. Nebraska: Board of Regents of the University of Nebraska, pp. 242-265. 
Crang M and Tolia-Kelly DP (2010) Nation, race, and affect: senses and sensibilities at national heritage sites. Environment and Planning A 42: 2315-2331.

Conradson D (2005) Landscape, care and the relational self: Therapeutic encounters in rural England. Health and Place 11: 337-348.

Dinnie E, Brown K, and Morris S (2013) Community, cooperation and conflict: negotiating the social well-being benefits of urban greenspace experiences. Landscape and Urban Planning 112: $1-9$.

Duckett PS and Pratt R (2001). The Researched Opinions on Research: Visually impaired people and visual impairment research. Disability and Society 16: 815-835.

Edensor T (2000) Walking in the British Countryside: Reflexivity, Embodied Practices and Ways to Escape. Body and Society 6: 81-106.

Flyvbjerg B (2006) Five misunderstandings about case study research. Qualitative Inquiry 12: 219-245.

Foley R (2017) Swimming as an accretive practice in healthy blue space. Emotion, Space \& Society 22: 43-51. 
Frumkin H, Bratman GN, Breslow SJ et al. (2017) Nature Contact and Human Health: A Research Agenda. Environmental Health Perspectives, https://doi.org/10.1289/EHP1663.

Gatrell A (2013) Therapeutic mobilities: walking and 'steps' to wellbeing and health. Health and Place 22: 98-106.

Harrington M (2015) Practices and meaning of purposive family leisure among working-and middle-class families. Leisure Studies 34(4): 471-486.

Hartig T, Mitchell R, de Vries S, et al. (2014) Nature and Health. Annual Review of Public Health 35: 207-228.

Horton J (2017) Disabilities, urban natures and children's outdoor play. Social and Cultural Geography 18: 1152-1174.

Imrie R (1999) The body, disability and Le Corbusier's conception of the radiant environment. In: Butler R and Parr H (eds) Mind and Body Spaces: geographies of illness, impairment and disability. Abingdon: Routledge, pp. 25-45.

Johnson VA (2017) Bringing Together Feminist Disability Studies and Environmental Justice. In: Ray SJ and Sibara J (eds) Disability Studies and the Environmental Humanities. Toward an Eco-Crip Theory. Nebraska: Board of Regents of the University of Nebraska, pp. 73-93. 
Kafer A (2017) Bodies of Nature: The Environmental Politics of Disability. In: Ray SJ and Sibara J (eds) Disability Studies and the Environmental Humanities. Toward an Eco-Crip Theory. Nebraska: Board of Regents of the University of Nebraska, pp. 201-241.

Kitchin R (1998) 'Out of Place', 'Knowing One’s Place': Space, power and the exclusion of disabled people. Disability \& Society 13(3): 343-356.

Macnaghten P and Urry J (1998) Contested Natures. London: Sage Publications Ltd.

Macpherson H (2009a) Articulating Blind Touch: Thinking through the feet. The Senses and Society 4(2): 179-193.

Macpherson $\mathrm{H}$ (2009b) The intercorporeal emergence of landscape: negotiating sight, blindness, and ideas of landscape in the British countryside. Environment and Planning A 41: 1042-1054.

Michalko R (1999) The Two in One Walking with Smokie, Walking with Blindness.

Philadelphia: Temple University Press.

Morales AL (2015) Foreword to the 2015 edition. In: Clare E Exile and Pride: Disability, Queerness, and Liberation. Durham: Duke University Press, pp. xi-xix. 
Morris J, O’Brien E, Ambrose-Oji B, Lawrence A, Carter C and Pearce A (2011) Access for all? Barriers to accessing woodlands and forests in Britain. Local Environment: The International Journal of Justice and Sustainability 16(4): 375-396.

Murray SA, McKay RC, and Nieuwoudt JM (2010) Grief and needs of adults with acquired visual impairments. The British Journal of Visual Impairment 28: 78-89.

Nocella II AJ (2017) Defining Eco-ability: Social Justice and Intersectionality of Disability, Nonhuman Animals, and Ecology. In: Ray SJ and Sibara J (eds) Disability Studies and the Environmental Humanities. Toward an Eco-Crip Theory. Nebraska: Board of Regents of the University of Nebraska, pp. 141-167.

Nyman SR, Dibb B, Victor CR and Gosney MA (2012) Emotional well-being and adjustment to vision loss in later life: a meta-synthesis of qualitative studies. Disability \& Rehabilitation 34: 971-981.

O'Brien L and Morris J (2014) Well-being for all? The social distribution of benefits gained from woodlands and forests in Britain. Local Environment: The International Journal of Justice and Sustainability 19: 356-383.

Ohly H, White MP, Wheeler BW, Bethel A, Ukomunne O, Nikolaou V, and Garside R (2016). Attention restoration theory: a systematic review of the attention restoration 
potential of exposure to natural environments. Journal of Toxicology and Environmental Health Part B 19(7): 305-343.

Özgünur H and Kendle AD (2006) Public attitudes towards naturalistic versus designed landscapes in the city of Sheffield (UK). Landscape and Urban Planning 74: 139-157.

Pamphilon B (1999). The Zoom Model: A dynamic framework for the analysis of life histories. Qualitative inquiry 5: 393-410.

Parr H and Butler R (1999) New geographies of illness, impairment and disability. In: Butler R and Parr H (eds) Mind and Body Spaces: geographies of illness, impairment and disability. Abingdon: Routledge, pp. 1-24.

Parr H (2008) Mental Health and Social Space. Oxford: Blackwell Publishing.

Paterson M (2014) Blindness, empathy, and 'feeling seeing': Literary and insider accounts of blind experience. Emotion, Space and Society 10: 95-104.

Pow C (2000). "Sense and sensibility": social-spatial experiences of the visually-impaired in Singapore. Singapore Journal of Tropical Geography 21: 166-182.

Ray SJ (2017) Risking Bodies in the Wild: The "Corporeal Unconscious" of American Adventure Culture. In: Ray SJ and Sibara J (eds) Disability Studies and the Environmental 
Humanities. Toward an Eco-Crip Theory. Nebraska: Board of Regents of the University of Nebraska, pp. 29-72 .

Ray SJ and Sibara J (2017) Introduction. In: Ray SJ and Sibara J (eds) Disability Studies and the Environmental Humanities. Toward an Eco-Crip Theory. Nebraska: Board of Regents of the University of Nebraska, pp. 1-25.

Reeve D (2002) Negotiating psycho-emotional dimensions of disability and their influence on identity constructions, disability and society. Disability \& Society 17(5): 493-508.

Rickard LN (2014) Mountains and Handrails: Risk, Meaning, and Responsibility in the Three National Parks. Environmental Communication 8(3): 286-304.

Riessman CK (2008). Narrative Methods for the Human Sciences. London: SAGE Publications Ltd.

Saerberg S (2010) "Just go straight ahead". The Senses and Society 5(3): 364-381.

Sensory Trust (2017) By all reasonable means: Least restrictive access to the outdoors. A guide produced by the Sensory Trust in collaboration with, and on behalf of, Natural Resources Wales [online]. Available at:

https://cdn.naturalresources.wales/media/682681/gn004-by-all-reasonable-means-leastrestrictive-access-to-the-outdoors.pdf [Accessed 16th November 2018]. 
Shakespeare T (2014) Disability Rights and Wrongs Revisited. Second Edition. Abingdon: Routledge.

Smaldone D, Harris C and Sanyal N (2005) An exploration of place as a process: the case of Jackson Hole, WY. Journal of Environmental Psychology 25: 397-414.

Small J (2015) Interconnecting mobilities on tour: tourists with vision impairment partnered with sighted tourists. Tourism Geographies 17(1): 76-90.

Smith J (2013) An archipelagic literature: reframing 'The New Nature Writing'. Green Letters 17(1): 5-15.

Stenning A and Gifford T (2013) Twentieth-century nature writing in Britain and Ireland. Green Letters 17(1): 1-4.

Thomas C (2007) Sociologies of disability and illness. Basingstoke: Palgrave.

Tregaskis C (2004) Applying the social model in practice: Some lessons from countryside recreation. Disability \& Society 16(6): 601-611. 
Wolf JB (2010) Against Breastfeeding (Sometimes). In: Metzl JM and Kirkland A (eds) Against Health: How Health Became the New Morality. New York: New York University Press, pp. 8392.

Worth N (2013). Visual Impairment in the City: Young People's Social Strategies for Independent Mobility. Urban Studies 50: 574-586. 